\title{
The Side Effects Of The Nonsteroidal Anti-Inflammatory Drug (NSAID) Ketoprofen On Histological And Ultrastructural Aspects Of The Kidneys Of Albino Rats
}

\author{
Amina M. Farag Allah \\ Zoology Department, Girls College for Arts, Science and Education \\ Ain Shams University
}

\begin{abstract}
The present work deals with the effect of the therapeutic dose of the nonsteroidal anti-inflammatory drug, ketoprofen on the microscopic structure of the kidney of the albino rat. The present study also sheds light on the risk of using over-dosage either by mistake or in an unwise attempt at quick relieving the body pain.

The intramuscular therapeutic dose of ketoprofen to albino rat was calculated and was found to equal $13.5 \mathrm{mg} / \mathrm{kg}$ body weight. Fifty adult male albino rats, Rattus norvegicus were used in the present study. The rats were equally allocated to five groups, each of 10 rats. Rats of the first group were kept as control. Rats of the second \& third groups were injected daily with the therapeutic dose of ketoprofen for four and eight successive weeks respectively. Rats of the fourth \& fifth groups were injected daily with double the therapeutic dose of ketoprofen for four and eight successive weeks respectively.

In rats given the therapeutic dose of ketoprofen daily for four weeks and sacrificed 24 hours after the last dose, light microscope examination showed that Malpighian corpuscles and the kidney tubules revealed signs of degeneration.

In rats given the therapeutic dose of ketoprofen daily for eight weeks the histological changes were in progression. A few numbers of glomeruli were increasingly congested and shrunken into dense masses of unrecognized structural details. The luminal borders of the cells lining the proximal convoluted tubules together with their microvilli were damaged.

The electron micrographs of ultrathin sections of kidneys of rats given the therapeutic dose of ketoprofen daily for eight weeks showed that the glomerular capillaries were disorganized and occasionally their lining endothelium showed degeneration. The podocytes showed deteriorated and rarefied cytoplasm; and their primary processes were fragmented. Also, the foot processes appeared occasionally broad. In some cells of proximal convoluted tubules the microvilli completely disappeared. Occasionally, these cells gave broad blebs into the tubule lumen which became almost obliterated. The cytoplasm of few cells lining the distal convoluted tubules became moderately rarefied and vacuolated.

In animals given double the therapeutic dose for four weeks many kidney glomeruli were fragmented and showed marked congestion and increased mesangium. The parietal walls of Bowman's capsules were damaged. The kidney tubules showed generalized hyalinization. A few numbers of t he tubule lining cells displayed pyknotic nuclei; some nuclei were karyolysed and even vanished.

In animals given daily double the therapeutic dose of ketoprofen for eight successive weeks, the glomeruli were sclerotic and necrotic and the kidney tubules showed generalized hyalinization.
\end{abstract}


In EM micrographs of kidney ultrathin sections, the configuration of the primary processes and the pedicels was greatly interrupted and disorganized. The capillary endothelium displayed signs of degeneration and disarray. The capillary basement membrane of the glomeruli exhibited regional attenuation or deformity. In some lining cells of the distal convoluted tubules, the cell organelles including mitochondria and lysosomes were noticeably electron dense, whereas the Golgi apparatus as well as the endoplasmic reticulum elements was degenerated.

\section{Introduction}

The nonsteroidal anti-inflammatory drugs (NSAID) are a valuable tool in the medical therapy of rheumatologic diseases. For this reason, their widespread use is understandable and generally justifiable.

Medical literature reveals several cases of drug - induced illness that leads to hospitalization. The nonsteriodal anti-inflammatory drugs were regarded to be responsible in the treated patients for various health problems, the most common of which is the occurrence of hepatic cirrhosis, decrease of the renal blood flow and of the rate of glomerular filtration as well as heart and sometimes renal failure (Lifschitz, 1983; Clive and Stoff, 1984;Dunn, 1984; Trost and Lemasters,1996 and Abdel Latief, 2002).

Ketoprofen is a new nonsteroidal anti-inflammatory drug derived from propionic acid (Insel, 1996). It has the following chemical structural formula:

\section{CH3}

\section{I}

\section{СНСОООН}

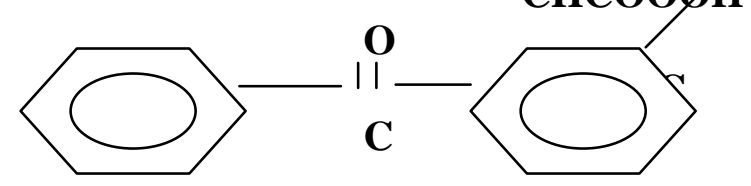

Ketoprofen is conjugated with glucuronic acid in the liver and excreted in the urine (Goodman and Gilman's 1996). It is used for treatment of musculo-skeletal disorders, such as rheumatoid arthritis, osteo-arthritis and ankylosing spondilitis (Higgs et al., 1980, and Craig and Stitzel, 1986). It acts by inhibiting cyclo-oxygenase, thereby reducing the production of prostaglandins and thromboxane (Simon and Millis, 1980). The sustained prostaglandin inhibition leads to sustained reduction in renal blood flow and thus the renal syndromes ensue (Adams et al.,1986)

The kidneys are the organs of choice in the present study. These organs have a unique importance; they excrete most waste products of metabolism, play a major role in controlling the water electrolyte balance within the body, maintain the acid-base balance of the blood, and produce the hormone erythropoietin concerned with blood formation, the hormone renin concer ned with control of blood pressure and active form the vitamin D (Cotran, 1987). Physicians deal with the cons equences of drug side effects on daily basis, but sound information about the basic microscopical pathology of such risk is usually hard to comeby. The present work deals with the effect of the therapeutic and double therapeutic dose of the non-steroidal anti-inflammatory drug, ketoprofen on the histology and ultrastructure of the kidneys of the albino rat. The double therapeutic dose tried in the present stydy to shed light on the risk of using over-dosage of the drug as it may occur either by mistake or in an unwise 
attempt at quick relieving the body pain.

\section{Material And Methods}

Ketoprofen used in the present study is manufactured by Amyria Factory Pharmaceutical Industries. The used vials are those containing 50mg of the drug-powder in each. In the present study the vials were reconstituted with $50 \mathrm{ml}$ of sterile saline. So, each, $1 \mathrm{ml}$ of the solution contained $1 \mathrm{mg}$ of the drug. The intramuscular therapeutic dose of ketoprofen to the rat was calculated according to the table given by Paget and Barnes (1964) and was found to equal $13.5 \mathrm{mg} / \mathrm{kg}$ body weight. Fifty adult male albino rats, Rattus norvegicus - each is $120-150 \mathrm{~g}$ in weight, and 4-5 months old - were used in the present study. They were obtained from the animal farm of the "Egyptian Organization for Vaccine and Biological Preparations" at Helwan, Cairo. The rats were maintained on standard diet and water ad libitum, and were equally allocated to five groups, each of 10 rats.

Group I: Control group, each rat was injected intramuscularly daily with physiological saline in amount equivalent to that used with the experimental animals.

Groups II \& III: Rats of these groups were injected daily with the therapeutic dose of ketoprofen for four and eight successive weeks respectively.

Groups IV \& V: Rats of these groups were injected daily with double the therapeutic dose of ketoprofen for four $\&$ eight successive weeks respectively.

After 24 hours of the last injections, the animals were sacrificed and rapidly dissected; their kidneys were excised and cut into small pieces.

For histological examination small pieces of kidneys were immediately fixed in Bouin's solution. Paraffin sections of $5 \mu \mathrm{m}$ thick were stained with hematoxylin and eosin (Humason, 1979).

For electron microscopic studies, kidney pieces were transferred immediately into $0.1 \mathrm{M}$ phosphate buffer $(\mathrm{pH} 7.2)$ at $4^{\circ} \mathrm{C}$ and then fixed in $3 \%$ glutaraldehyde and $1 \%$ paraformaldehyde in $0.1 \mathrm{M}$ phosphate buffer $(\mathrm{pH} 7.2)$ at $4^{\circ} \mathrm{C}$ for 10 minutes. Kidney pieces were then washed in the phosphate buffer for 60 minutes, postfixed in $1 \%$ osmium tetroxide in $0.1 \mathrm{M}$ phosphate buffer for one hour, dehydrated through ascending series of ethyl alchohol, cleared in propylene oxide and embedded in Araldite gelatin capsules (Weakley, 1981).

Semithin sections $(0.5-1 \mu \mathrm{m})$ were stained with toluidine blue for light microscopic examination to determine the area of interest prior to ultrathin sectioning. Silver ultrathin sections $\left(50^{\circ}\right.$ A) were prepared, stained with uranyl acetate and lead citrate and examined and photographed on 400T electron microscope at the EM unit, Specialized Hospital, Ain Shams University.

\section{Observations}

\section{Group I: (Control Animals):}

Representative micrographs of the histological sections and the ultrathin sections of kidney cortex from the control group are shown in Figs.1,2,3 and 4.

Group II: (Rats given the therapeutic dose of ketoprofen daily for four weeks):

\section{A) Light Microscopy:}

In rats given the therapeutic dose of ketoprofen daily for four weeks, the histological preparations of the kidneys showed some degenerative changes. Few glomeruli were atrophied, while others were clefted or acquired bizarre profile (Fig. 5). Moreover, a few 
glomeruli were markedly congested (Fig.6). The urinary spaces of some Malpighian corpuscles were evidently widened (Figs.5\&6). The kidney tubules showed variable degrees of degener ation (Figs.6 - 9). The lining cells of few kidney tubules were necrotic and their nuclei were pyknotic (Figs. 6\&7). Besides, cells lining few kidney tubules were broken down and vanished (Fig.7). Cell casts were observed in some kidney tubules (Fig.8). Figure (5) shows that the kidney interstitium revealed signs of inflammation (interstitial nephritis). Many of the interstitial capill -aries were congested (Figs.5\&9) where marked cellular exudates in certain areas are indicative of chronic inflammation.

Group III: (Rats given the therapeutic dose of ketoprofen daily for eight weeks):

\section{A) Light Microscopy:}

The histological changes in this group were in progression. A few numbers of glomeruli were increasingly congested and shrunken into dense mass of unrecognized structural details (Fig.10). In such glomeruli, the capillary network was markedly disturbed. Also, the kidney tubules showed widespread degeneration. (Figs.10 - 12). Cell debris were shown released into the lumina of some tubules (Fig.11). The lumina of few tubules were almost obliterated by virtue of such debris. Characteristically, the luminal borders of the cells lining the proximal convoluted tubules together with their microvilli were damaged (Fig.12). The endothelial cells of some kidney tubules were markedly swollen and these swellings were so obvious that these cells almost blocked the lumina of tubules indicating intertubular haemorrhages brought about by extravasted blood. (Fig.13). The interstitial tissue showed interstitial nephritis. (Fig.12)

\section{B) The Electron Microscopy:}

The electron micrographs of kidneys of rats given the therapeutic dose of ketoprofen daily for eight weeks showed highly disturbed glomerular architecture (Fig.14). The glomerular capillaries were disorganized and occasionnally their lining endothelium showed degeneration (Figs.14 - 16). The podocytes showed deteriorated and rarefied cytoplasm; the fibrillar cytoskeleton was markedly manifested (Fig.15). Occasionally, the primary processes of the podocytes were fragmented (Fig.16). Also the foot processes appeared occasionally broad; this might result from extensive foot processes fusion. The broad foot processes displayed degenerated cytop lasm. Besides, the glomeruli showed increased mesangium.

Inspection of the electron micrographs of the proximal convoluted tubules revealed many degenerative changes under the effect of such drug (Figs.17\&21). The microvilli of these cells showed variable degrees of degeneration. In some cells of proximal convoluted tubules the microvilli completely disappeared (Fig.17). In some tubules the lining cells gave broad blebs into the tubule lumen which became almost obliterated (Fig.18). The cytoplasm of some lining cells of the proximal convoluted tubules showed structureless wide irregular areas that had high electron density (Fig.19). Some mitochondria of these cells displayed degeneration or grouped in clusters (Figs.20\&21). The basal infoldings of these cells were poorly developed (Fig.20). Small vacuoles were developed in the ground cytoplasm. The nuclei of some cells became lucent and amorphous and lacked the heterochromatin (Fig.21). Some nuclei showed pyknotic appearance (Fig.18). 
The electron micrographs of the distal convoluted tubules showed variable degrees of damage. The cyto plasm of few cells became moderately rarefied and vacuolated (Fig.22). The luminal surface of such cells was broken down. Some mitochondria showed degeneration while others acquired abnormal structural configuration. Nuclear blisters were occasionally formed and peripheral chromatin clumps appeared (Fig.22).

Group IV: (Animals injected daily with double the therapeutic dose of ketoprofen for four successive weeks):

\section{A: Light microscopy:}

In rats given double the therapeutic dose for four weeks many kidney glomeruli were fragmented (Fig.23) and showed marked congestion and increased mesangium (Fig.24). In some instances, the parietal walls of Bowman's capsules were damaged. The kidney tubules showed generalized hyalinization. A few numbers of the tubular lining cells displayed pyknotic nuclei; some nuclei were karyolysed and even vanished (Fig.23). Congestion and haemorrhage together with inflammatory signs - interstitial nephritis -were also shown (Fig.23).

Group V: (Animals injected daily with double the therapeutic dose of ketoprofen for eight successive weeks):

\section{A) Light microscopy:}

In animals given daily double the therapeutic dose of ketoprofen for eight successive weeks, some kidney glomeruli appeared fractured and fragmented (Fig.25). Other glomeruli were apparently congested and manifested increased mesangium. In some cases, the area of contact between glomerulus and Bowman's capsule i.e. the area at the urinary pole of the glomeruli - became widened thus making the urinary space narrow (Fig.26). Rarely, amorphous structureless and solidified glomeruli were shown; apparently they are sclerotic and necrotic (Figs.26 \& 27).

Besides, the kidney tubules showed generalized hyalinization (Fig.25). Some kidney tubules suffered great damage; their epithelial cells displayed lysed cytoplasm and pyknotic or vanished nuclei (Fig.28). However, the lining cells of some kidney tubules were so swollen that the lumina of these tubules were obliterated (Fig.26). The renal tissue showed interstitial nephritis (Fig.29). Besides, the intra-renal blood vessels were congested (Fig.27).

\section{B) The Electron Microscopy:}

In EM micrographs of kidney ultrathin sections, the three structural components of the glomerular capill aries showed signs of deterioration. The cytoplasm of the podocytes appeared rarefied (Fig.30). The configuration of the primary processes and the pedicels was greatly interrupted and disorga nized (Figs.30\&31). The capillary endothelium exhibited signs of degeneration and disarray. The capillary basement membrane of the glomeruli exhibited regional attenuation or deformity (Figs.30 \& 31).

The cells of the proximal convoluted tubules showed vacuolization; the developed vacuoles were of variable sizes and shapes. Occasionally, some vacuoles became confluent with each other (Fig.32). In some cells, spherical structureless electron-lucent bodies were shown inside the cytoplasm (Fig.33). Besides, a number of mitochondria were damaged (Fig.33). In some tubules the lumen contained amorphous debris that underwent various degrees of lysis (Fig.33).

Some lining cells of the distal convoluted tubules showed lysis. In these cells the cytoplasm lost its 
structural organization and embodied many irregular vacuoles. The nuclei showed irregular rarefied patches. Cell casts were shown in the lumina of such distal tubules (Fig.34). The cell organelles, including mitochondria and lysosomes were noticeably electron dense, whereas the Golgi apparatus as

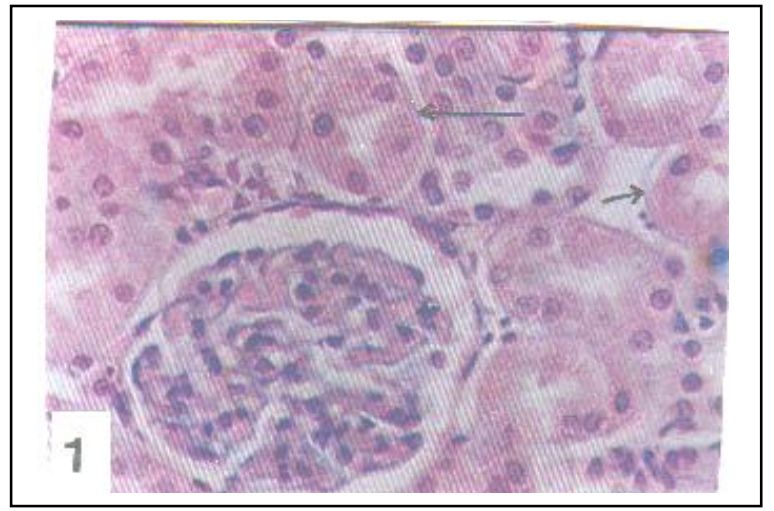

Figure (1): A photomicrograph of a kidney section of control rat showing a part of control cortical region containig Malpighian corpuscle, proximal (Long arrow) and distal convoluted tubules (short arrow). X 400

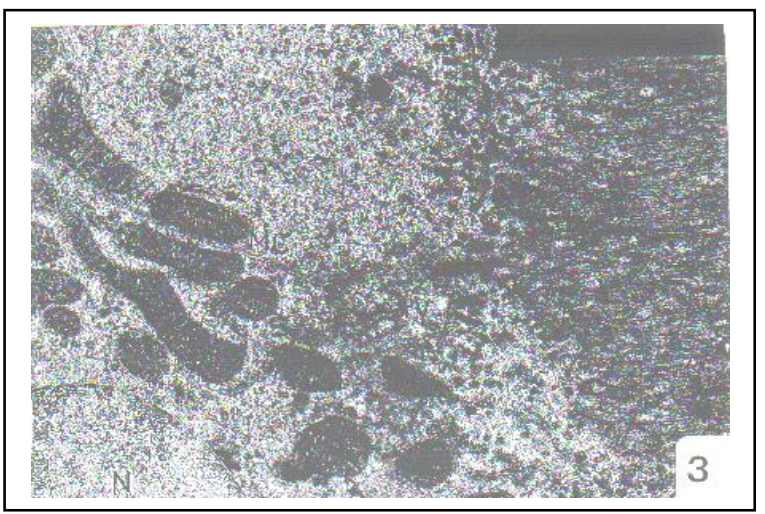

Figure (3): An electron micrograph of a part of a proximal convoluted tubule of control rat kidney. Notice the microvilli (MV), the spherical central nucleus $(\mathrm{N})$, multiple elongate mitochondria $(\mathrm{M})$, the pinocytotic vesicles (PV) and the two cell neighbouring membranes and their tight junction (TJ). X 12000 well as the endoplasmic reticulum elements were degenerated (Figs.33\& 34). Furtherly advanced with doubling of the therapeutic dose, conspicuously damaged basal membrane infoldings were evident. This was in addition to an abundance of lipid droplets and degenerative vacuoles (Fig.34).

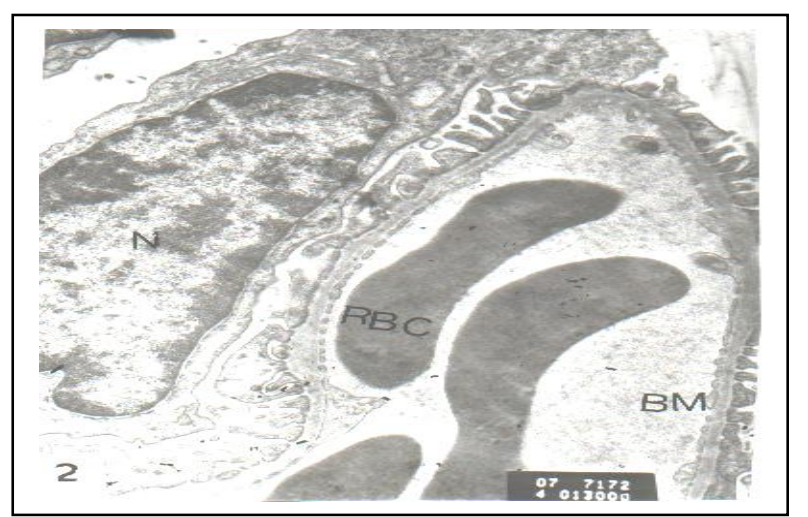

Figure (2): An electron micrograph of a part of a glomerulus of a kidney of control rat. Notice the erythrocyte (RBC) within the capillary. The capillary is lined with thin fenestrated endothelial cells (Ec). X 13000

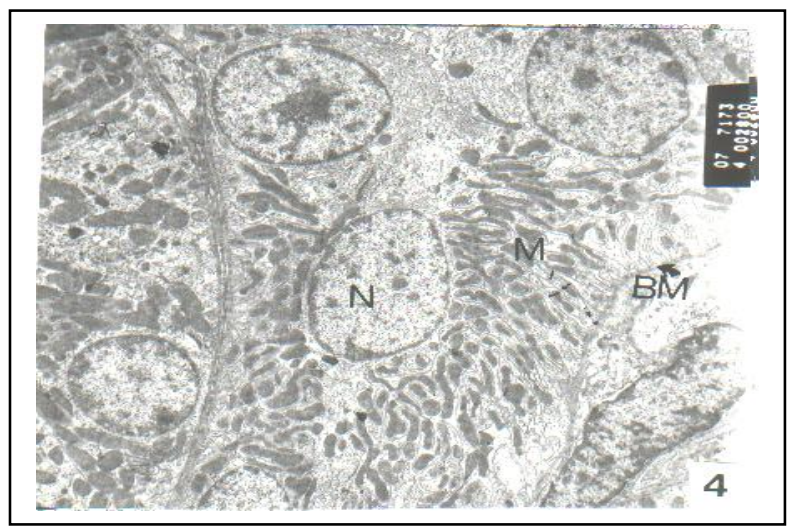

Figure (4): An electron micrograph of a part of a distal convoluted tubule of control rat showing the infolding of the basal membrane (BM), a large number of mitochondria (M). Notice the lumen (LU) of such tubule. X 2800 


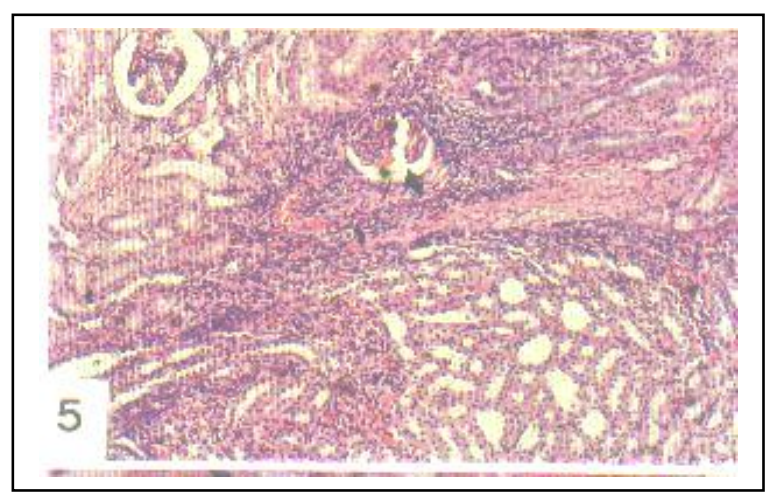

Figure (5): T.S. of kidney of rat treated daily with the therapeutic dose of ketoprofen for four weeks showing interstitial nephritis. Notice that the glomeruli are clefted (head arrow). X 100

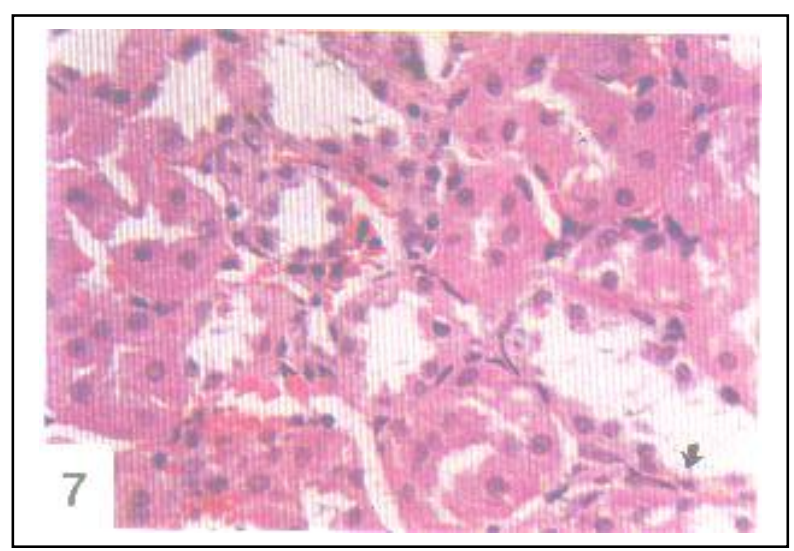

Figure (7): T.S. of kidney of rat treated daily with the therapeutic dose of ketoprofen for four weeks showing tubular damage. Notice that few lining cells the renal tubules are vanished (arrow). X 400

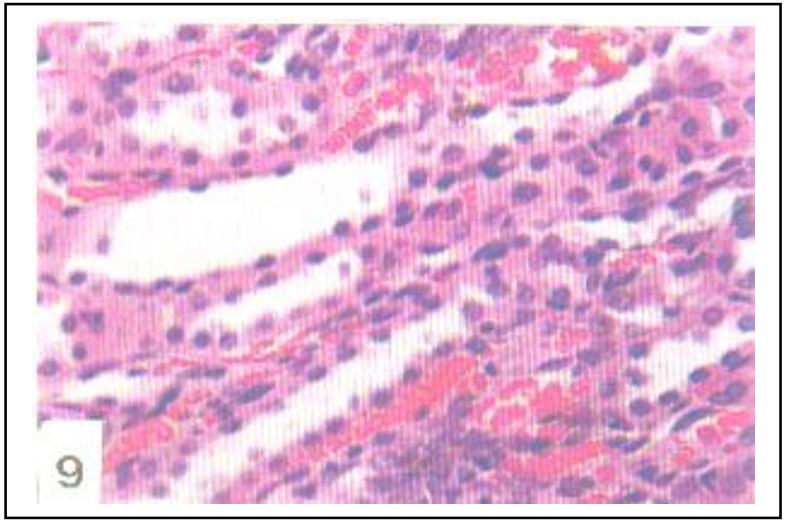

Figure (9): T.S. of kidney of rat treated daily with the therapeutic dose of ketoprofen for four weeks. Notice that the interstitial capillaries are congested. X 400

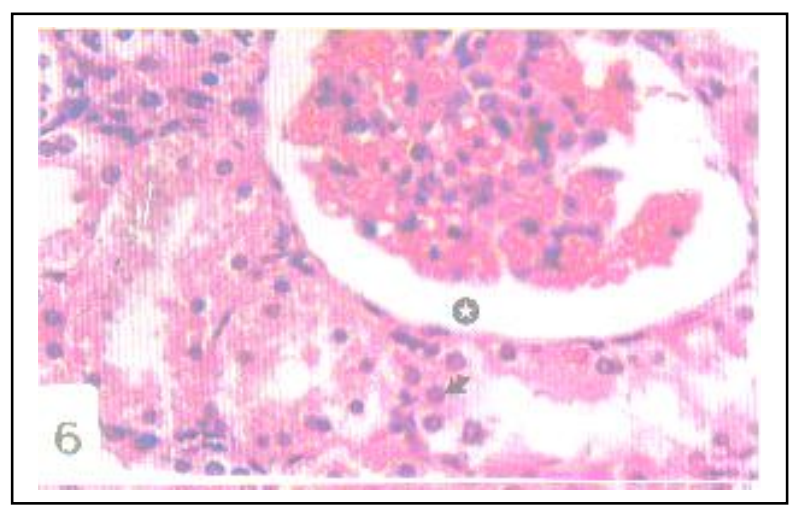

Figure (6): T.S. of kidney of rat treated daily with the therapeutic dose of ketoprofen for four weeks showing congested glomerulus and widened urinary space (star). Notice the damage of kidney tubules as manifested by cell necrosis (Spot) and nuclear pyknosis (arrow).

X 400

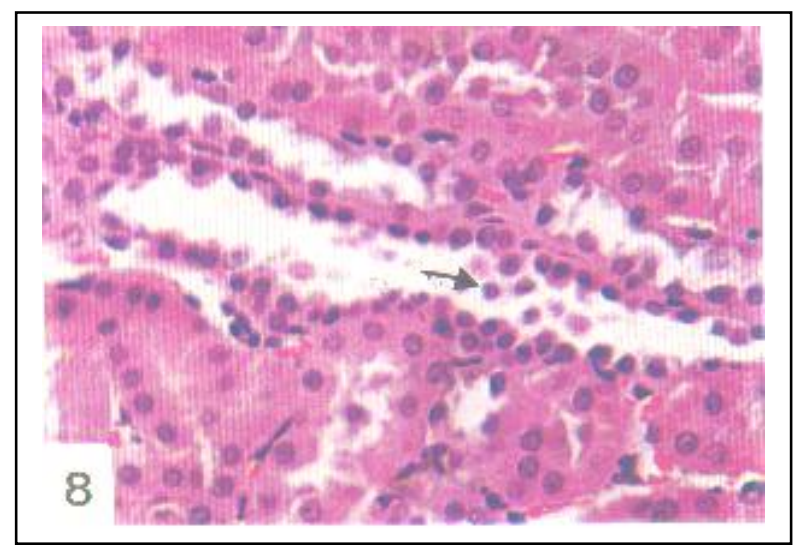

Figure (8): T.S. of the kidney of rat treated daily with the therapeutic dose of ketoprofen for four weeks. Notice cell costs (arrow) in the lumina of some tubules. X 400

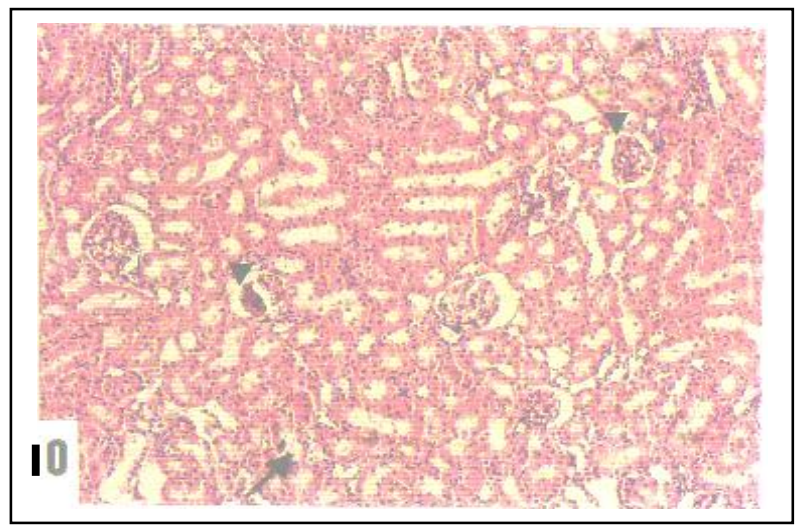

Figure (10): T.S. of kidney of rat treated daily with the therapeutic dose of ketoprofen for eight weeks showing shrunken glomeruli (head arrow). Notice the degenerated renal tubules (arrow). X 400 
The Side Effects Of The Nonsteroidal .......

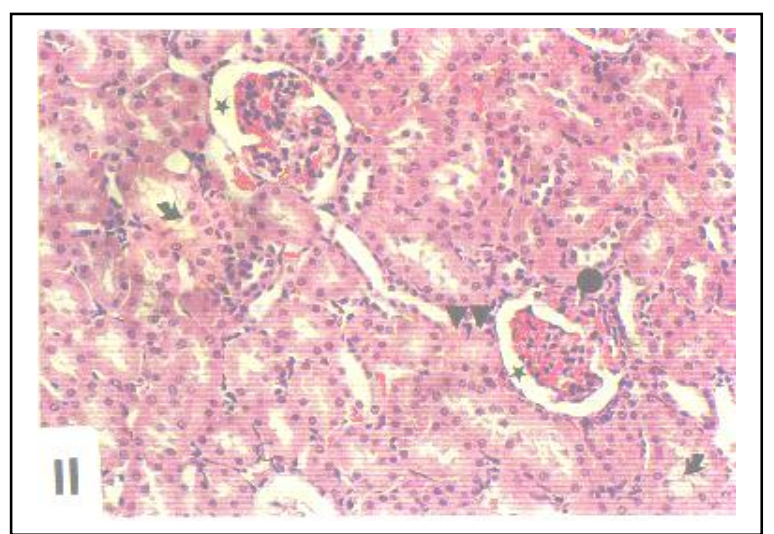

Figure (11): T.S. of Kidney of rat treated daily with the therapeutic dose of ketoprofen for eight weeks showing shrunken and congested glomeruli (star) and the lining cells of the renal tubules are necrotic (head arrow). Notice cell debris and casts in the lumina of some tubules (arrow). X 200

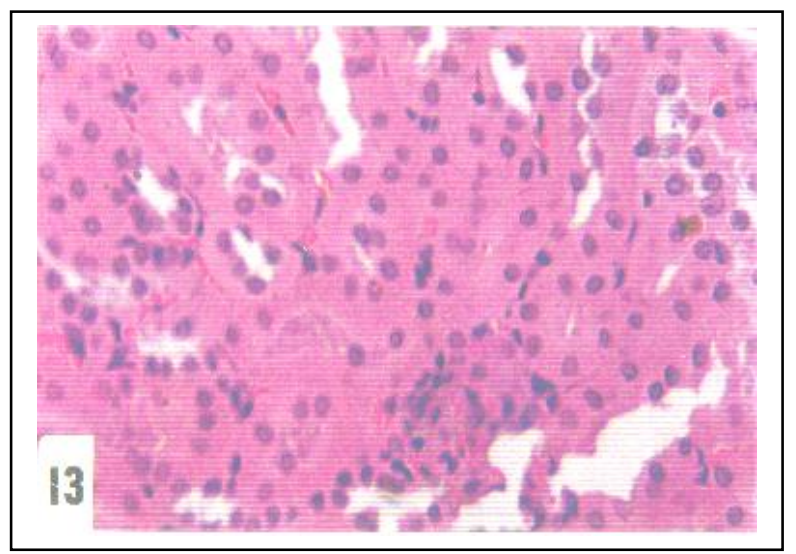

Figure (13): T.S. of kidney of rat treated daily with the therapeutic dose of ketoprofen for eight weeks showing the obliteration of the lumina of many kidney tubules. X 400

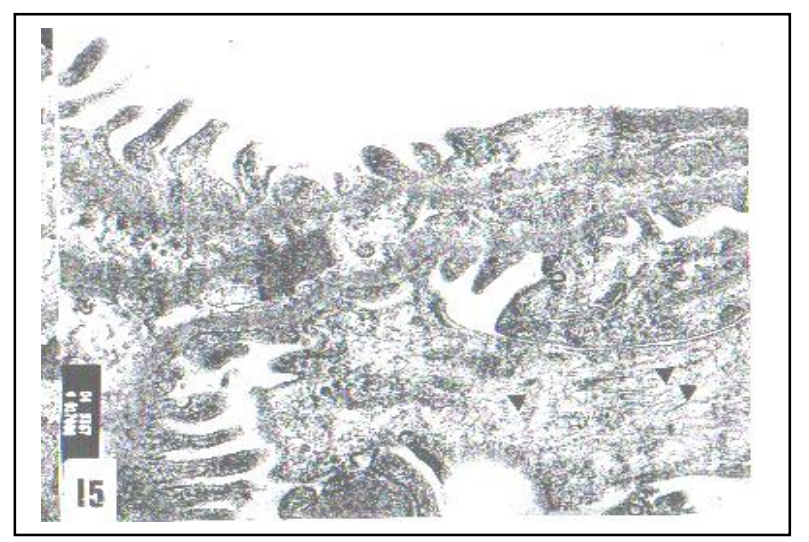

Figure (15): An electron micrograph of a glomerular capillary of a kidney of rat treated daily with the therapeutic dose of ketoprofen for eight weeks showing the rarefied cytoplasm of the podocytes and the fibrillar cytoskeleton is markedly manifested (arrow head). X 17000

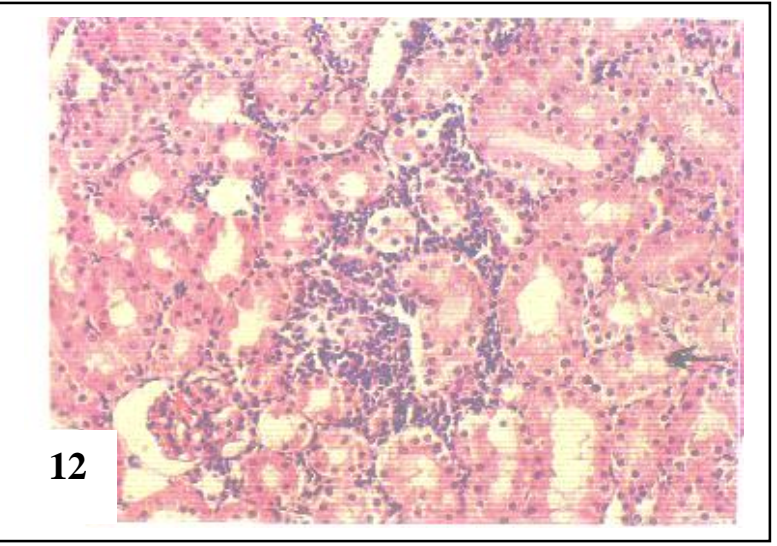

Figure (12): T.S. of kidney of rat treated daily with the therapeutic dose of ketoprofen for eight weeks showing the interstitial nephritis and degeneration of kidney tubules (arrow). X 200

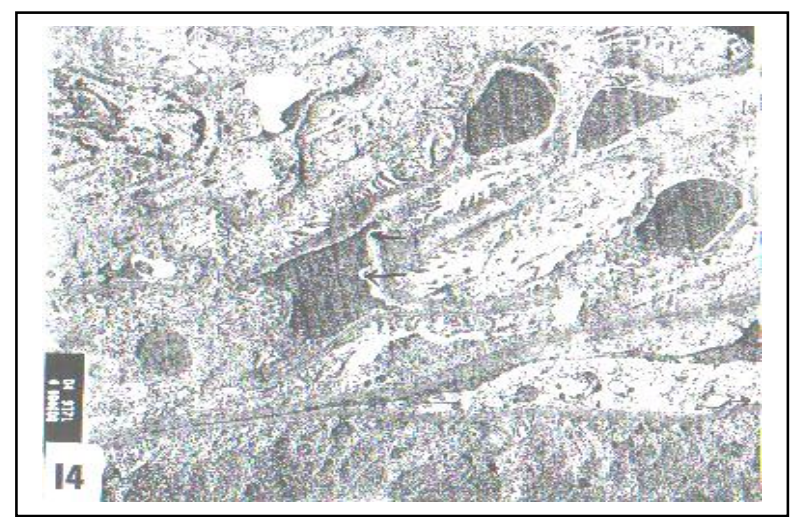

Figure (14): An electron micrograph of a glomerulus of a kidney of rat treated daily with therapeutic dose of ketoprofen for eight weeks. Notice that the lining endothelium of the glomerular capillaries are disorganized and degenerated (arrows).X 4600

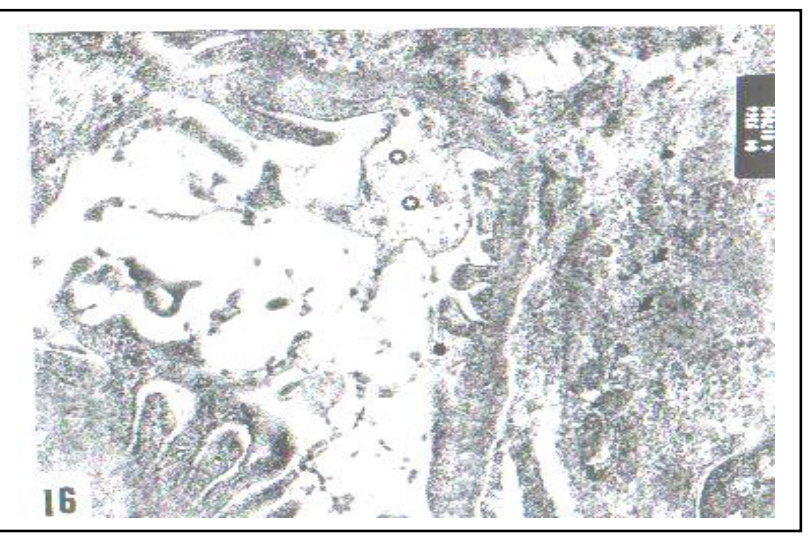

Figure (16): An electron micrograph of a glomerulus of a kidney of rat treated daily with the therapeutic dose of ketoprofen for eight weeks showing that some of the podcytes primary processes podocytes are fragmented and some foot processes appear broad and exhibiting degenerated cytoplasm (star). Notice that the glomeruli showed increased mesangium (arrow). X 17000 


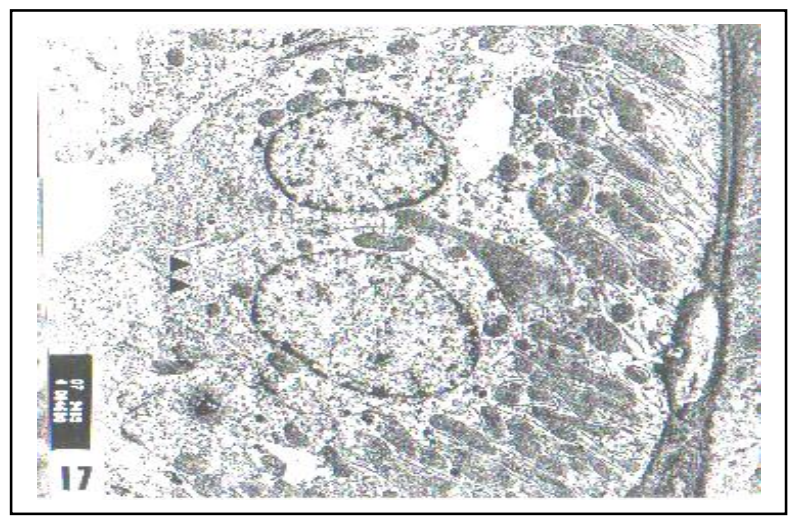

Figure (17): An electron micrograph of parts of proximal convoluted tubules of kidney of rat treated daily with the therapeutic dose of ketoprofen for eight weeks showing the disappearance of the the microvilli (arrowhead). $\mathrm{X} 4600$

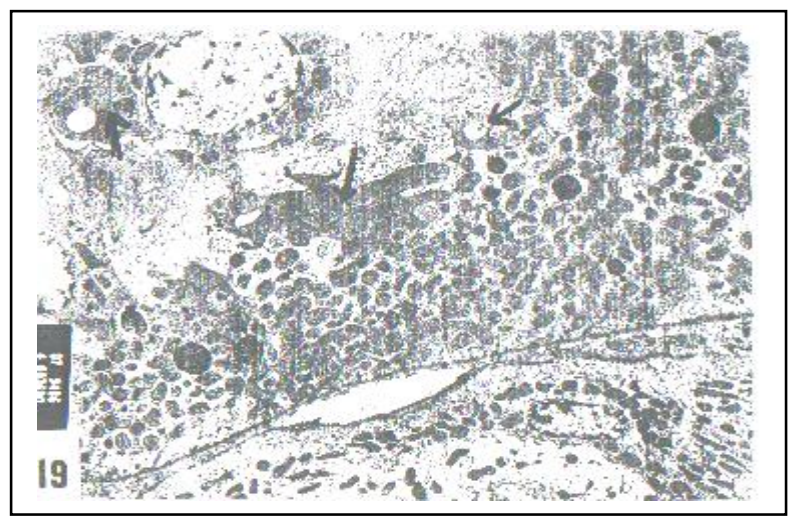

Figure (19): An electron micrograph of a proximal convoluted tubule of kidney of rat treated daily with the therapeutic dose of ketoprofen for eight weeks showing irregular electron dense patches in the cytoplasm of the lining cells (arrows). X 3600

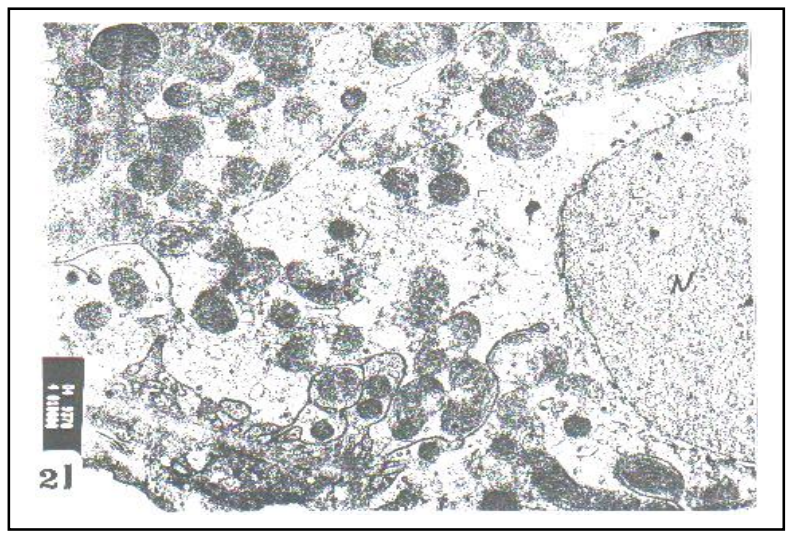

Figure (21): An electron micrograph of cell of proximal convoluted tubule of kidney of rat treated daily with the therapeutic dose of ketoprofen for eight weeks. Notice that the nucleus (N) lacks the heterochromatin. X 10000

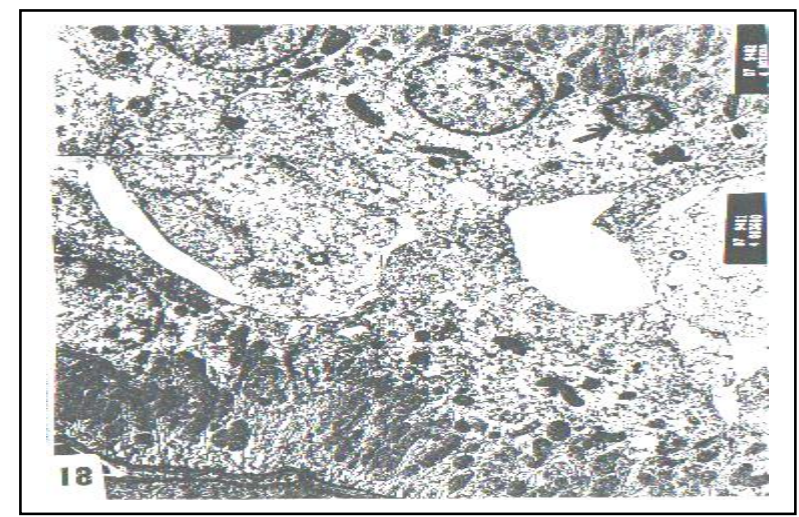

Figure (18): An electron micrograph of a proximal convoluted tubules of kidney of rat treated daily with the therapeutic dose of ketoprofen for eight weeks showing that the lining cells give broad blebs in the tubule lumen which appear almost obliterated (star). Notice the highly shrunken nucleus (arrow) X 3600

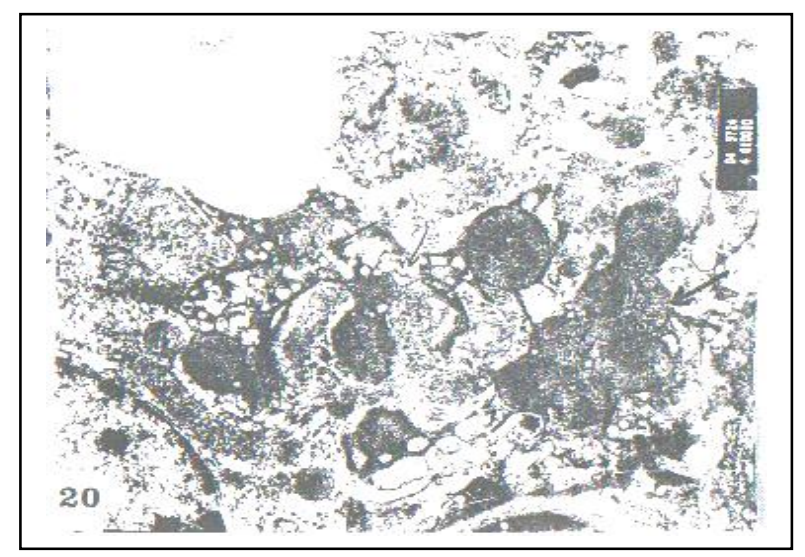

Figure (20): An electron micrograph of a proximal convoluted tubule of kidney of rat treated daily with the therapeutic dose of ketoprofen for eight weeks. Notice that the mitochondria are occasionally grouped into clusters (thick arrows) and small vacuoles (thin arrow) are developed in the ground cytoplasm. X 1000

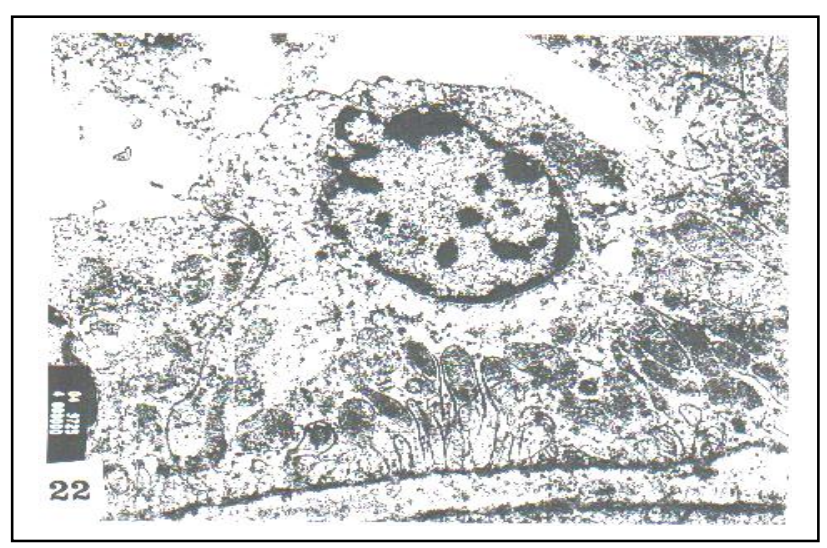

Figure (22): An electron micrograph of part of distal convoluted tubule of kidney of rat treated daily with the therapeutic dose of ketoprofen for eight weeks showing the rarefied and vacuolation of the cytoplasm and degeneration of few mitochondria. Notice the nuclear blisters and peripheral chromatin clumps. X 10000 


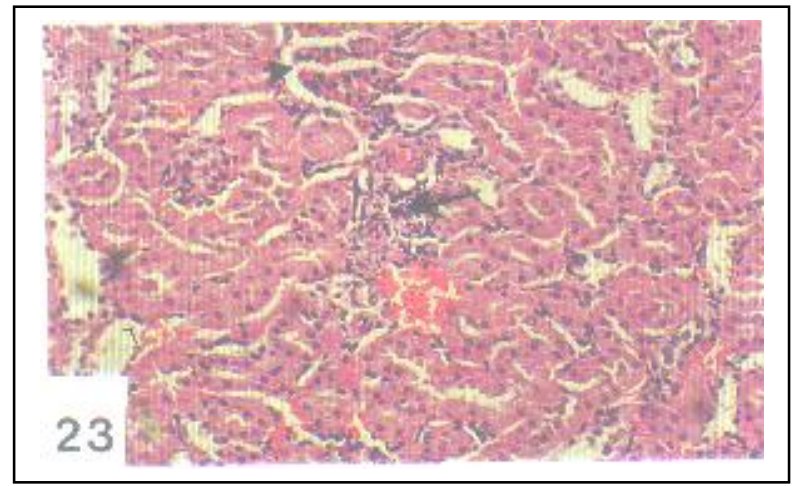

Figure (23): T.S. of kidney of rat treated daily with double the therapeutic dose of ketoprofen for four weeks showing glomerulus is fragmented. Notice the congestion of the blood vessels and pyknois of nuclei of the renal tubule cells. X 100

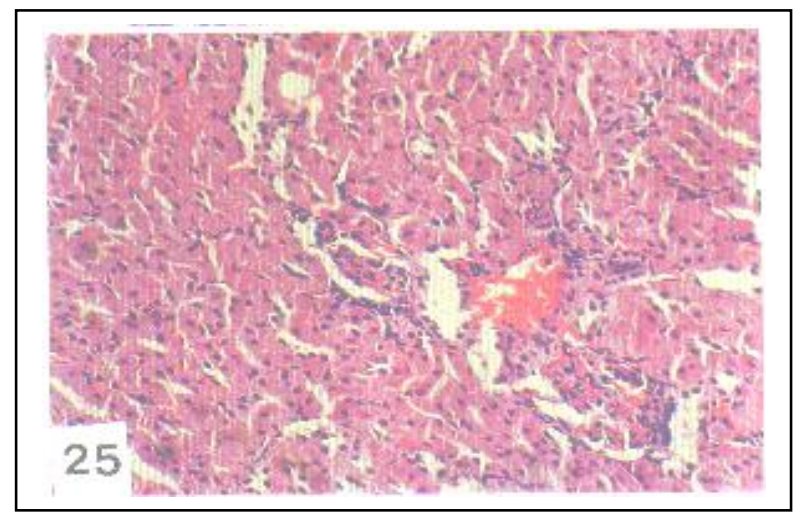

Figure (25): T.S. of kidney of rat of treated daily with double the therapeutic dose of ketoprofen for eight weeks showing that the glomeruli are fructured and fragmented. Notice that the kidney tubules are hyalinized and blood the vessel is congested. X 100

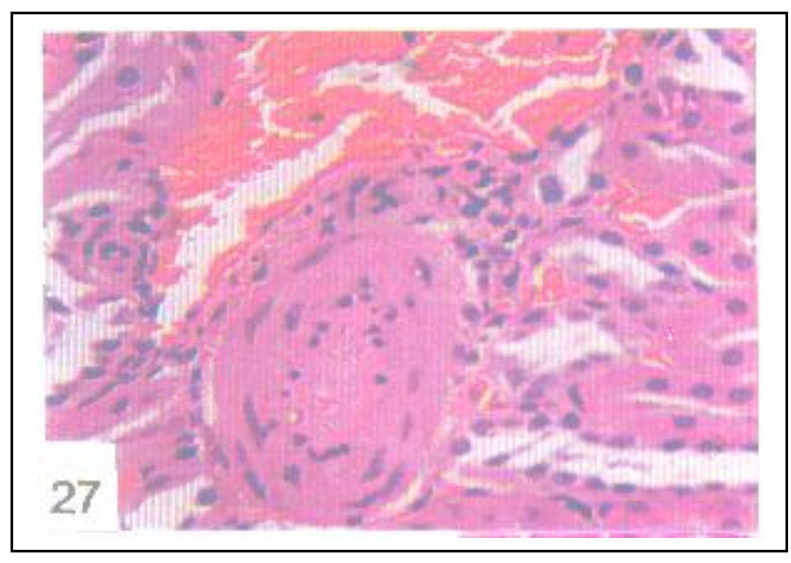

Figure (27): T.S. of kidney of rat treated daily with double the therapeutic dose of ketoprofen for eight weeks showing the sclerotic glomerulus. Notice that the blood vessel is congested. X 400

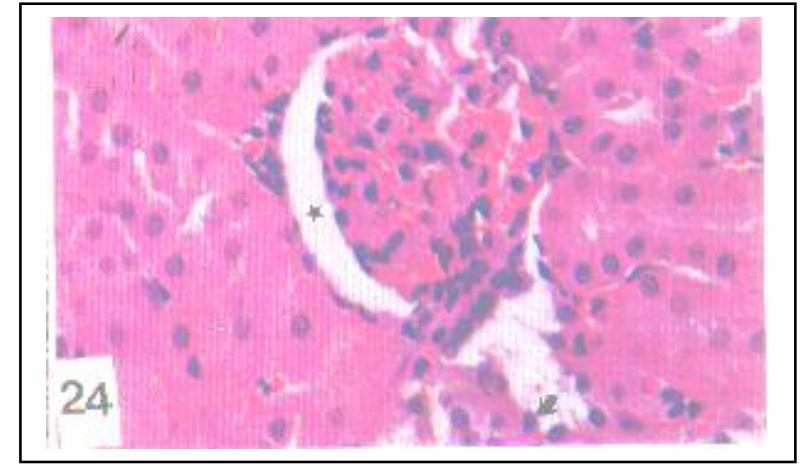

Figure (24): T.S. of kidney of rat treated daily with double the therapeutic dose of ketoprofen for four weeks showing that the glomerulus is congested and displays increased mesangium. X 400

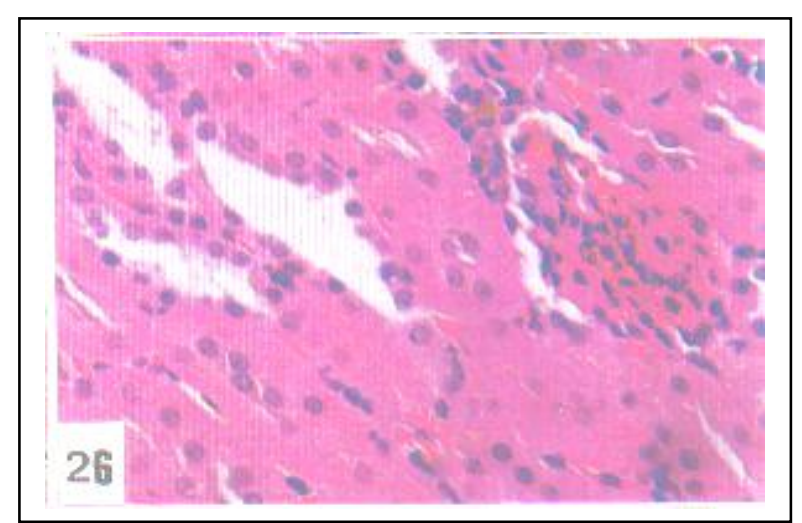

Figure (26): T.S. of kidney of rat treated daily with double the therapeutic dose of ketoprofen for eight weeks showing that the urinary space is narrow and that the lining cells of renal tubules are swollen with subsequent obliteration of the lumina of renal tubules. X 400

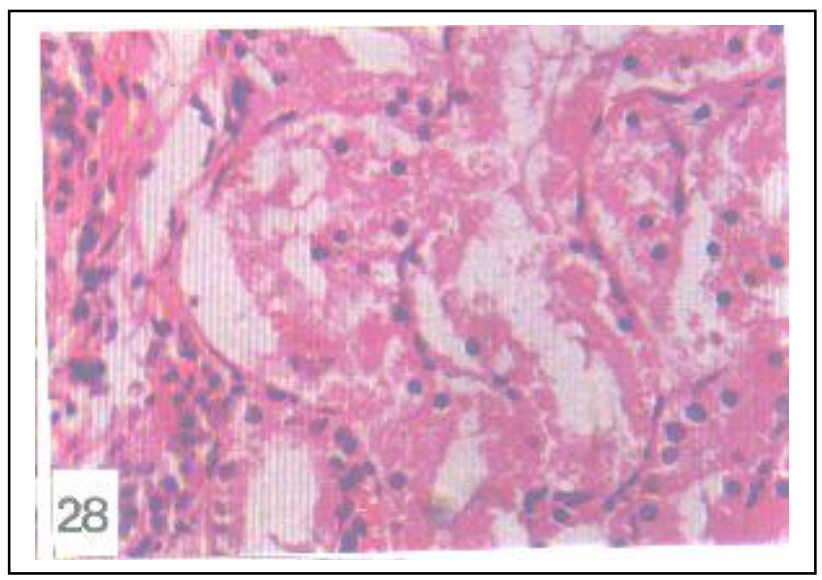

Figure (28): T.S. of kidney of rat treated daily with double the therapeutic dose of ketoprofen for eight weeks showing that the epithelial cells of renal tubules manifest lysed cytoplasm and pyknotic or vanished nuclei. X 400 


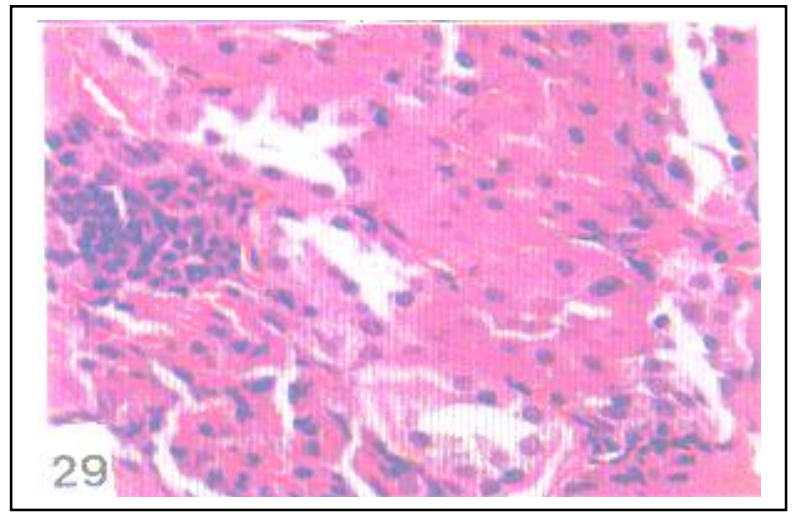

Figure (29): T.S. of kidney of rat treated daily with double the therapeutic dose of ketoprofen for eight weeks. Notice the degeneration of kidney tubules and development of interstitial nephritis. X 400

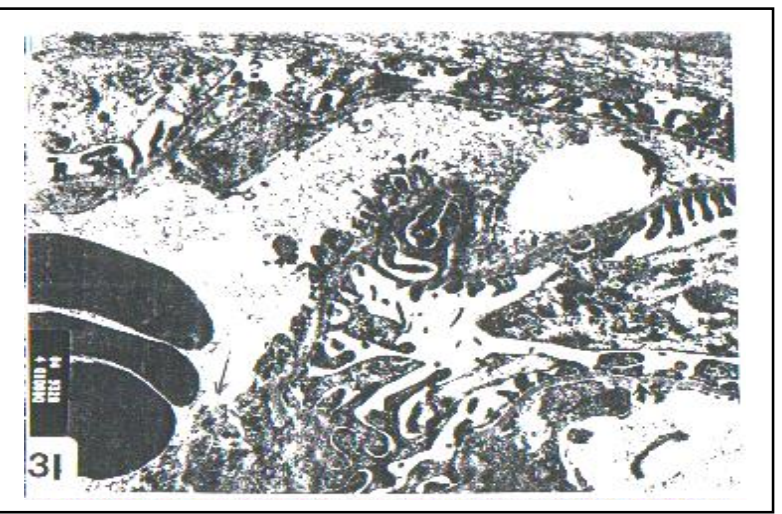

Figure (31): An electron micrograph of glomerulus of kidney of rat treated daily with the double therapeutic dose of ketoprofen for eight weeks showing the attenuation (short arrow) and capillary basement membrane (long arrow). X 10000

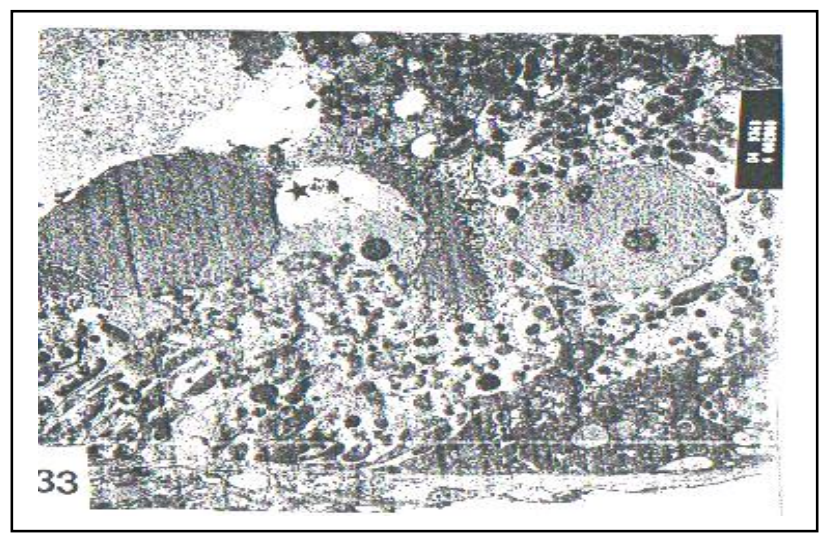

Figure (33): An electron microrgraph of a part of proximal convoluted An electron micrograph of a part of proximal convoluted tubule of kidney of rat treated with double the therapeutic dose of ketoprofen for eight weeks. Notice the degeneration of few mitochondria and the absence of heterochromatin in the nucleus. The tubule lumen contains amorphous debris (star). X 2800

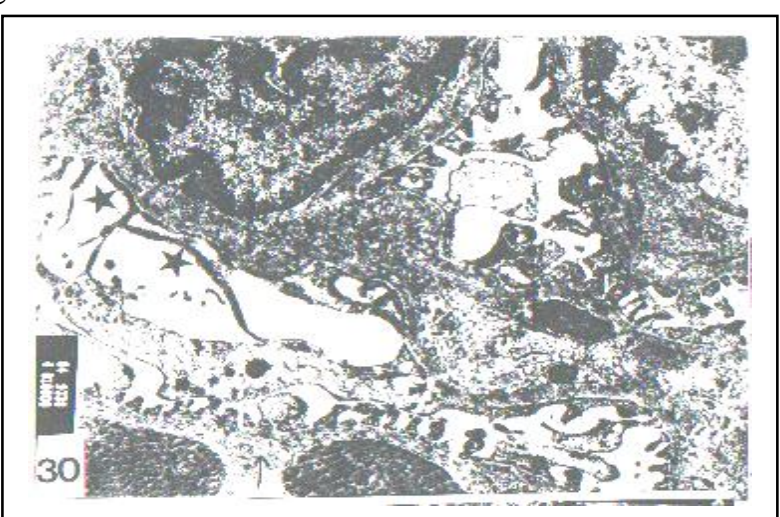

Figure (30): An electron micrograph of glomerulus of kidney of rat treated daily with the double therapeutic dose of ketoprofen for eight weeks showing the attenuation (short arrow) and deformity (long arrow) of the capillary basement membrane. Notice the disorganization of the primary podocytes and pedicles (star). X 10000

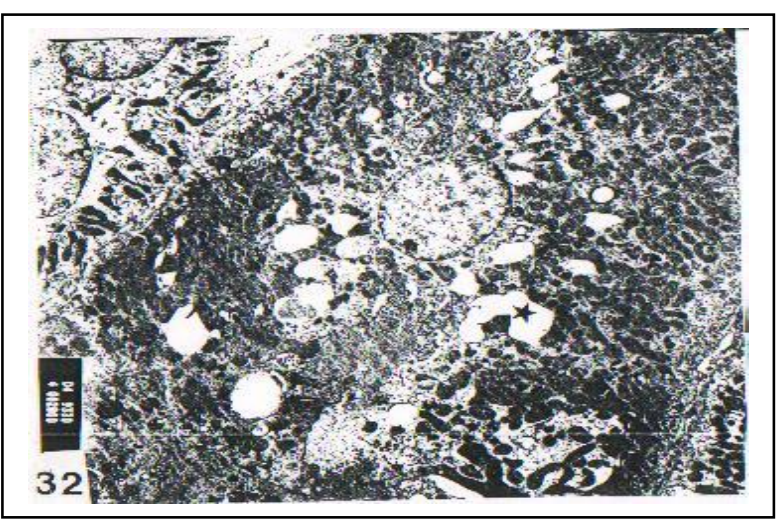

Figure (32): An electron microrgraph of a part of proximal convoluted tubule of kidney of rat treated with the double the therapeutic dose of ketoprofen for eight weeks. Notice that the cytoplasm is vacuolated and that some vacuoles are confluent with each other (star). X 2800

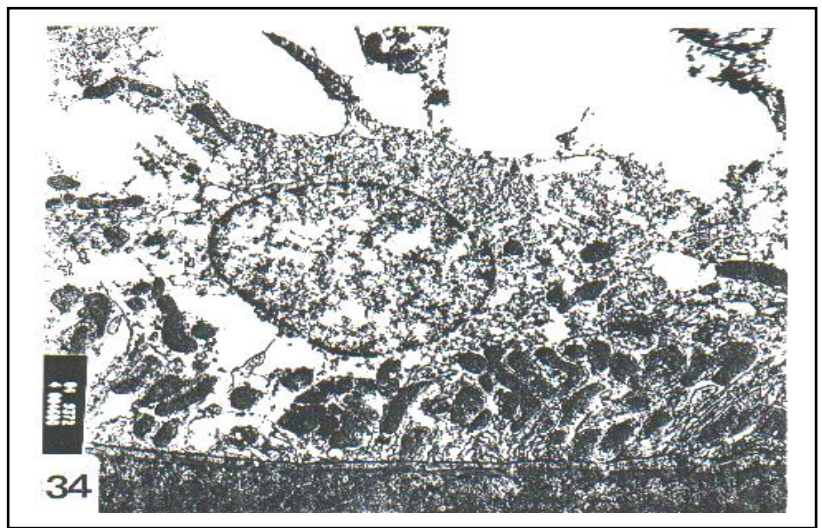

Figure (34): An electron micrograph of a cell of distal convoluted tubule of kidney of rat treated with double the therapeutic dose of ketoprofen for eight weeks. Notice the degenerated, rarefied and lysed cytoplasm and rarified patches in the nucleus. X 4600 


\section{Discussion}

It is widely accepted that the nonsteroidal anti-inflammatory drugs (NSAID) act by inhibiting cylooxygenase, thereby reducing the production of prostaglandins, and thromboxane (Simon and Mills, 1980). The sustained prostaglandin inhibition leads to sustained reduction in the renal blood flow and thus the renal syndrome ensues (Adams, et al., 1986). The present study spotted histological and ultrastructural changes accompanying the renal syndrome resulting from the nonsteroidal anti-inflammatory drug, ketoprofen.

The present study revealed that in case of using therapeutic dose of ketoprofen for four weeks some glomeruli became shrunken and clefted. However, prolonged usage of such drug for eight weeks induced more morphological deterioration in the glomeruli; also more glomeruli were affected. However, on using double the therapeutic dose for eight weeks few glomeruli displayed increased mesangium and became structureless and sclerotic. These findings generally agree with earlier studies on the effect of nonsteroidal anti-inflammatory drugs on kidney. Brezin et al., (1979) and Bender et al., (1984) reported hyaline and sclerotic glomeruli in patients treated with fenoprofen. Adams et al., (1986) reported the development of glomerular tip lesion in patients treated with ketoprofen. Likewise, AbdelGawad (1991) and D'Agati (1996) observed nercotized glomeruli and glomerulosclerosis in albino rats after long-term administration of piprofen and asprin respectively. Also, AbdelKader et al., (1998) noticed atrophied glomeruli and ruptured parietal layer of Bowman's capsules in rats treated with indomethacin.
Ketoprofen effect was found in electron micrographs of the present study to induce the fusion of the foot processes of the podocytes and the fragmentation of the primary processes of such cells. It is well-known that the main function of the podocytes is mechanical; their secondary processes (pedicles) support the hydrostatic pressure exerted on the basement membrane during filtration. So, it is reasonable to interpret that demolishing the construction of the podocytes may adversely affect the filtration process. Berzin et al., (1979), Lorch et al.,(1980), Finkelstein et al., (1982) and Bender et al., (1984) reported effacement and fusion of the epithelial foot processes in patients under the effect of fenoprofen (NSAID). Henry and Tange (1994) and Faas et al., (1997) observed that treatment of rats with asprin caused disruption of the trilaminated structure of the glomerular basement membrane with marked fusion of the podocyte foot processes and increase of the mesangial matrix. In the present study regional attenuation and deformity in the capillary basal lamina of the kidney glomeruli of animals given double the therapeutic dose of ketoprofen for eight weeks were observed. It is well-known that the basement membrane is the only continuous structure separating the blood contained in the capillary from the capsular space. It is documented that the glomerular basement membrane is a selective macromolecular filter and which acts as a physical filter as an electrical barrier (Junqueira et al., 1995). So, deformity in the construction of the capillary basal lamina would adversely affect the glomerular filtrate.

The present study revealed that ketoprofen induced damage of the 
microvilli of the proximal convoluted tubules. Besides, cell casts were spotted in the lumina of such tubules. The electron micrographs showed that the cytoplasm of such cells became rarefied and vacuolated. The basal infoldings of some of the proximal convoluted tubule cells were poorly developed. Also, the present work showed that some nuclei of kidney tubules displayed peripheral chromatin clumping under the effect of the therapeutic dose of ketoprofen. It is well-known that this change is reversible. However, the observed lucent nuclei in the kidney tubules under the effect of therapeutic or double the therapeutic dose of ketoprofen indicate an irreversible change (Brown and Locrshin , 1981).

Fong and Cohen (1982) reported that the anti-inflammatory drug, ibuprofen, induced acute necrosis of the cells of proximal tubules, loss of the brush border of these cells and poorly developed basal infoldings. Adams et al., (1986) described kidney tubular damage in patients treated with ketoprofen for six months. Moreover, Hemida and Abdel-Kader (1998) found that indomethacin induced degeneration of the epilthelial layer lining the proximal convoluted tubules in kidney of rats accompanied with appearance of casts in some tubules. In addition, Reinfeld et al., (1998) and El Ridi and Rahmy (2000) reported that treatment with the NSALDs induced kidney tubular damage, erosion of microvilli and accumulation of many vacuoles in the cytoplasm of proximal convoluted tubules. The deformations occurring in the cells of the proximal tubules reported in the present study under the effect of ketoprofen bear importance since the glomerular filtrate found in the renal capsule passes into the proximal convoluted tubules, and the process of resorption and excretion begins there.
The present study revealed that ketoprofen induced interstitial nephritis even on giving the therapeutic dose of the drug for only four weeks. Acute interstitial nephritis has been reported with most of the NSAIDs (Finkelstein et al., 1982; Bender et al., 1984; Olsen et al., 1986; and Sorour et al., 1990). The potential role of $\mathrm{T}$ cell-mediated mechanisms in the production of interstitial nephritis has been demonstrated (Finkelstein et al., 1982).

The present study further indicates that hyper-dosage of ketoprofen exacerbated the pathological criteria shown in the kidney tubules if compared with those resulting from using the therapeutic dose. These accentuated adverse consequences of the drug calls from the strict use of USAIDs under careful medical supervision.

\section{REFERENCES}

1. Abdel-Gawad, S. (1991): The histological pictures of the kidney and adrenal gland of albino rat after long-term administration of acetyl salcylic acid and pirprofen. Egypt. J. Histol., 14 (1): 97 - 106.

2. Abdel-Kader, F; Hemieda, S. and Abdel Hady, S., (1998): Physiological and histopathological changes in rats treated with indomethacin. J. Egypt. Ger. Soc. Zool., 26 (C) Histology \& Histochemistry, 31-52.

3. Abdel-Latief, H.M.(2002): Studies On The Side Effects of an Anticancer Drug and/or NonSteroidal Anti-inflammatory Drug on the Liver of Albino Rat. M.Sc. Thesis, Girl's College,Ain Shams University.

4. Adams, D.; Michael, J. and Bacon, P.; Howie, A; Mc Conkey, 
B. and Adu, D.: (1986): Nonsteroidal anti-inflamatory drugs and renal failure. Lancet, 11: 57-60.

5. Bender, W.; Whelton, A.; Beschorner, W.; Darwish, M.; Hall-Graggs, M. and Solez, K. (1984): Interstitial nephritis, proteinuria, and renal failure caused by nonsteroidal anti-inflammatory drugs. Am. J. Med., 76: 1006-1012.

6. Brezin, J.; Moriber, S.; Schwartz, A. and Chinitz, J. (1979): Reversible renal failure and nephrotic syndrome associated with nonsteroidal anti-inflammatory drugs. N.Eng.J.Med., $\underline{301}$ (23): 1271-1273.

7. Brown, D. and Lockshin, $R$. (1981): Cell Death In Biology And Pathology. First Ed., Chapan and Hall - London - New York.

8. Clive, D. and Stoff, J. (1984): Renal syndromes associated with nonsteroidal anti-inflammatory dru gs. N. Eng. J. Med., 310: 563-572.

9. Cortan,R.S.(1987): The kidney and its collecting system. Chapter 14,in Basic Pathology, edited by Robbins and Kumar,1987,W.B. Saunders company,London, Philadelphia.

10. Craige, C. and Stitzel, R. (1986): Modern Pharmacology, second edition, Little, Brown and Company, Boston and Toronto, pp. 1029-1030.

11. D' Agati, V. (1996): Does aspirin cause acute or chronic renal failure in experimental animals and in humans? Am. J. Kid. Diseases, 28 (1): 24-29.

12. Dunn, M. (1984): Non-steroidal anti-inflammatory drugs and renal function. Am. J. Med., 35: 411-428.

13. El-Ridi, M. and Rahmy, T. (2000): Action of Vitamin $\mathrm{C}$ against acetaminophen-induced hepatorenal toxicity in rats. Egypt. J. Histol, (in press).
14. Faas, M., Schuiling, G.; Baller, J.; Valkhof, A. and Bakker, W. (1997): Aspirin treatment of lowdose-entotoxin-treated pregnant rat: patho-physiologic and immunohistologic aspects., J. Lab. Clin. Med., 130 (5): 496-508.

15. Finketstein, A.; Fraley, D. and Stachura, I. (1982): Fenoprofen nephropathy: Lipoid nephrosis and interstitial nephritis. Am. J. Med., 72: 81-87.

16. Goodman and Gilman's (1996): The Pharmacological Basis of Therapeutics. $8^{\text {th }}$ ed. pp. $614-640$ Pergamon Press, New York, Tokyo.

17. Lifchitz, M. (1983): Renal effects of nonsteroidal anti-inflammatory agents. J. Lab. Clin. Med., 102: 313323.

18. Henry, M. and Tange, J. (1994): Ultrastructural appearance of acute renal papillary lesions induced by asprin. Pathol., 139(1): 57-67.

19. Higgs, G.; Eakin, K. Moncada, S, and Vane, J. (1980): The effects of nonsteroidal anti-inflammatory drug on leucocyte migration in carrageenin induced inflammation. Euro J. Pharmcol., 66: 81-86.

20. Humason, G. (1979): Animal Tissue Techniques. $4^{\text {th }}$ ed., San Francisco, W. H. freeman and Company.

21. Janqueira, L.; Carneiro, J. and Robert, K. (1995): Basic Histology, $8^{\text {th }}$ edition, Appleton and Medical Publication, Norwalk, California, pp., 306-319.

22. Lifchitz, M.(1983):Renal effects of nonsteroidal anti-inflammatory age nts. J.Lab.Clin.Med., 102: 313-323.

23. Lorch, J,; Lefavour, G.; Davidson, $H$. and Cortell, $S$. (1980): A case of fenoprofeninduced nephrotic syndrome and renal failure. (letter).Ann. Int.Med., 93(3): 5091. 
24. Oslen, F.; Wassef, N.; Olsen, H. and Hansen, H. (1986): Ultrastructure of the kidney in acute interstitial nephritis, Ultrastruct. Pathol.,10: 1-16.

25. Paget, G, and Barnes, J. (1964): Toxicity Tests in Evaluation of Drug. Activities, Pharmacometric. ED Laurence, D. and Bachorach A. $\mathrm{PbI}$. Academic Press, London and New York. Chapter 6, pp. 135-166.

26. Reinfeld, D. A.; Olesnicky, L.; Pirani, C. L. and Appel, G.B.(1998): Nephrotic syndrome associated with the use of the nonsteroidal anti-inflammatory drugs, Case report and review of the Literature.Nephron 37(3):174-179.

27. Simon, I. and Millis, J. (1980): Nonsteroidal anti-inflammatory drugs. N. Engl. J. Med. 302: 11741185, 1237-1243.

28. Sorour, H; Moussa, K., and Abdel-Ghaffar, E. (1990): Effect of voltaren on the structure of male albino rat kidney. Egypt. J. Histol., 13 (1): 31-38.

29. Trost,L.and Lemasters,J. (1996): The mitochondrial permeabilty transition:A new pathophysiological mechanism for Reye's Syndrome and toxic liver injury J.Pharm.Exp. Therap.,78(3):1000-1005.

30. Weakly, B.: (1981): Beginner's Handbook in Biological Transmission Electron Microscopy, $2^{\text {nd }}$ ed., Churchill Livingstone., London. 


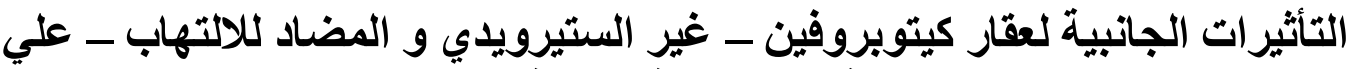

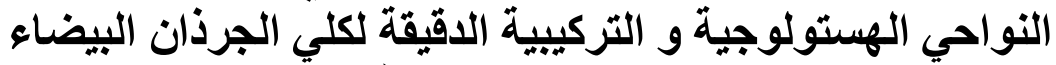

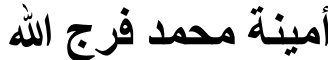

قسم علم الحيوان ـ كلية البنات للآداب و العلوم و التربيةـ جامعة عين شمس

يتناول هذا البحث در اسـة تأثنير الجرعات العلاجية من عقار كيتوبروفين - المضـاد للإلتهابـات - علي التركيب الهستولوجي الإني و التركيب الدقيق للكلي باستخدام المجهر الإلكتروني، كذلك تمت در اسة تأثنير الجرعات المتز ايدة من هذا

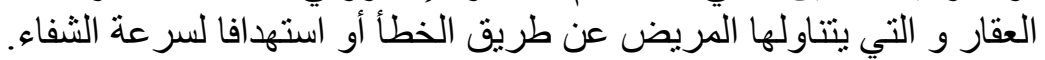

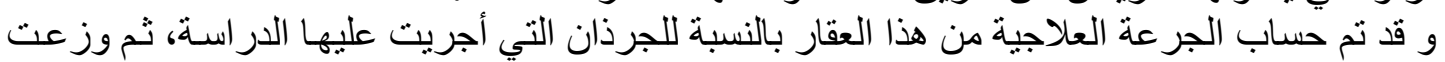

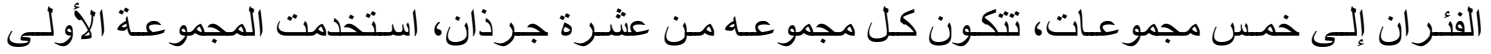

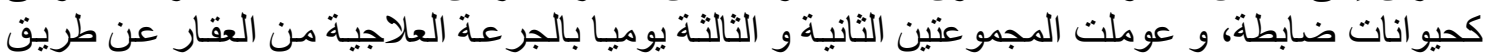

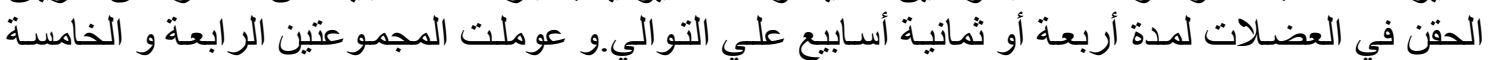

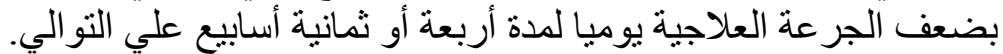
و قد أوضحت الدراسة الهستولوجيه تأثر الخصائص التركية كيبية لكريات ملبيجي و الأنيبيات الملتفة

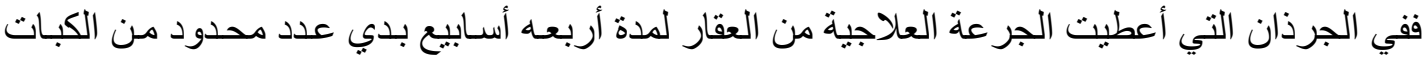

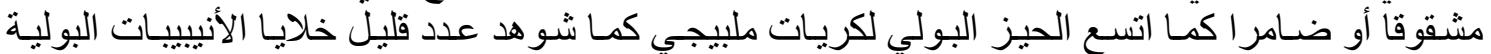

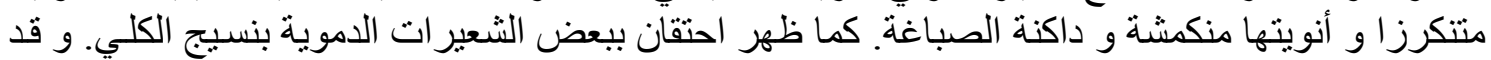

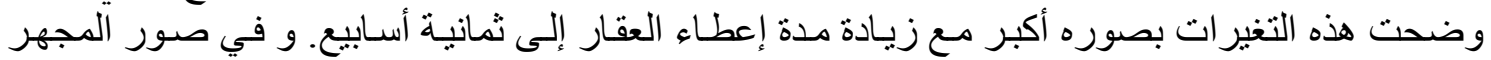

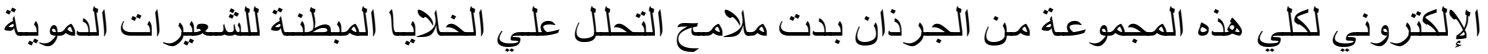

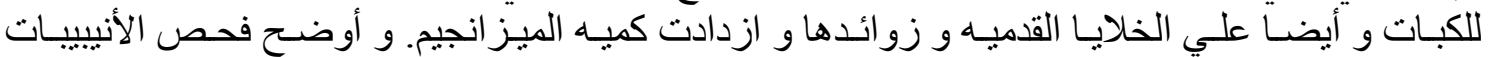

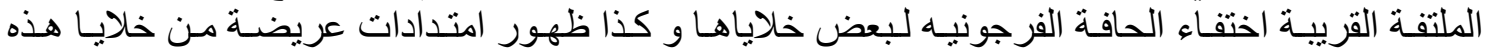

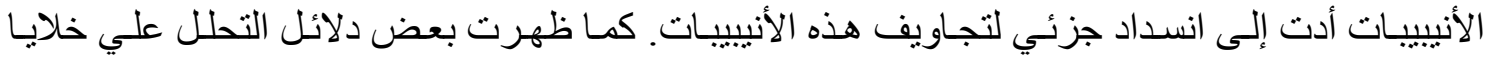
الأنيبيات الملتفة البعيدة.

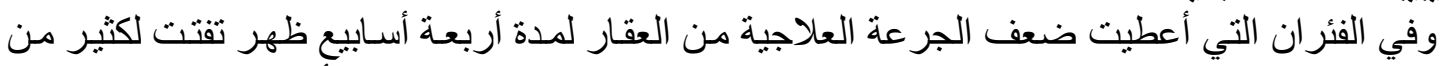

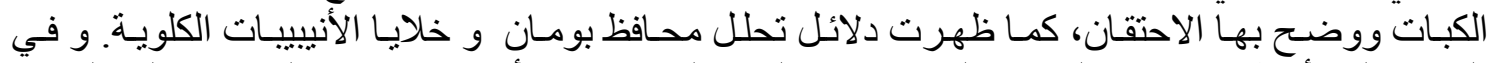

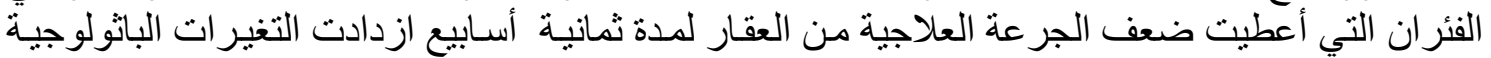

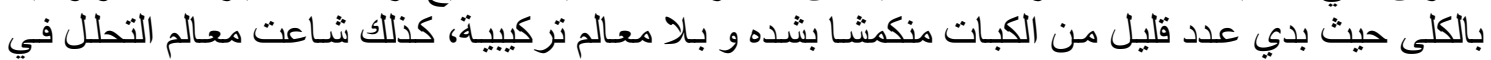

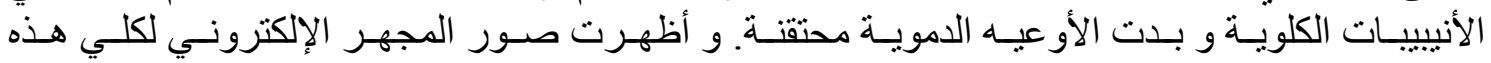

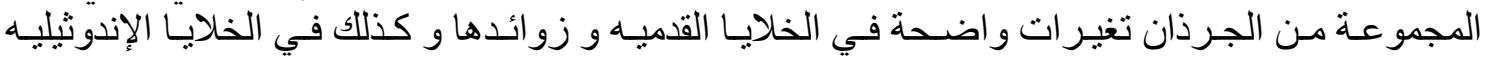

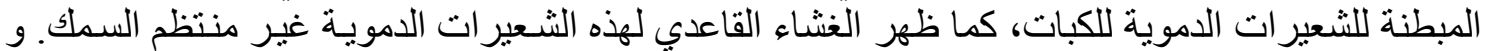

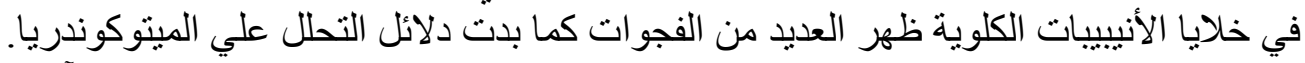

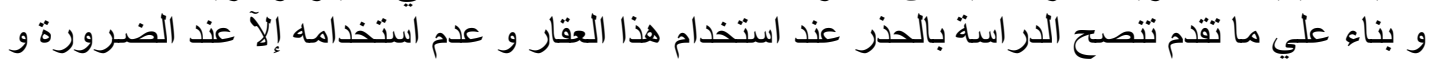

